\title{
Identification of putative interactions between swine and human influenza A virus nucleoprotein and human host proteins
}

\author{
Alex Generous ${ }^{\dagger}$, Molly Thorson ${ }^{\dagger}$, Jeff Barcus, Joseph Jacher, Marc Busch and Heidi Sleister ${ }^{*}$
}

\begin{abstract}
Background: Influenza A viruses (IAVs) are important pathogens that affect the health of humans and many additional animal species. IAVs are enveloped, negative single-stranded RNA viruses whose genome encodes at least ten proteins. The IAV nucleoprotein (NP) is a structural protein that associates with the viral RNA and is essential for virus replication. Understanding how IAVs interact with host proteins is essential for elucidating all of the required processes for viral replication, restrictions in species host range, and potential targets for antiviral therapies.

Methods: In this study, the NP from a swine IAV was cloned into a yeast two-hybrid "bait" vector for expression of a yeast Gal4 binding domain (BD)-NP fusion protein. This "bait" was used to screen a Y2H human HeLa cell "prey" library which consisted of human proteins fused to the Gal4 protein's activation domain (AD). The interaction of "bait" and "prey" proteins resulted in activation of reporter genes.

Results: Seventeen positive bait-prey interactions were isolated in yeast. All of the "prey" isolated also interact in yeast with a NP "bait" cloned from a human IAV strain. Isolation and sequence analysis of the cDNAs encoding the human prey proteins revealed ten different human proteins. These host proteins are involved in various host cell processes and structures, including purine biosynthesis (PAICS), metabolism (ACOT13), proteasome (PA28B), DNA-binding (MSANTD3), cytoskeleton (CKAP5), potassium channel formation (KCTD9), zinc transporter function (SLC30A9), Na+/K+ ATPase function (ATP1B1), and RNA splicing (TRA2B).

Conclusions: Ten human proteins were identified as interacting with IAV NP in a Y2H screen. Some of these human proteins were reported in previous screens aimed at elucidating host proteins relevant to specific viral life cycle processes such as replication. This study extends previous findings by suggesting a mechanism by which these host proteins associate with the IAV, i.e., physical interaction with NP. Furthermore, this study revealed novel host protein-NP interactions in yeast.
\end{abstract}

Keywords: Influenza A virus, Nucleoprotein, Yeast two-hybrid, Host restriction

\section{Background}

Influenza A viruses (IAVs) are important pathogens that affect the health of humans and many additional animal species. In humans, seasonal IAV infection presents as a non-fatal, uncomplicated, acute infection characterized by the presence of upper respiratory symptoms as well as fever, headache, soreness and fatigue lasting $2-5$ days [1]. However, deaths from seasonal IAV infections often

\footnotetext{
* Correspondence: heidi.sleister@drake.edu

${ }^{\dagger}$ Equal contributors

Biology Department, Drake University, 1344 27th St., Des Moines, IA 50311, USA
}

\section{Biomed Central}

arise when the normal flu symptoms are exacerbated by compromised immunity or age [1]. In addition to seasonal influenza A viruses, pandemic strains periodically appear causing increased mortality rates. For example, the 1918 Spanish flu resulted in approximately 50 million human deaths [2]. The most recent pandemic resulted from the emergence of the swine-origin H1N1 virus [3,4]. Due to influenza A's potential for mortality, high mutation rates (resulting in genetic drift) and pandemic potential (resulting from genetic reassortment), it is critical to learn more about the virus, especially as it pertains to virulence, 
transmissibility, and identification of potential targets for development of therapeutics.

Influenza A viruses exhibit a broad host range beyond humans [5]. Waterfowl serve as the central reservoir species. In addition to humans, various IAV subtypes circulate in pigs, poultry, horses, dogs as well as other species. Subtypes ( $\mathrm{H} 1 \mathrm{~N} 1$ and $\mathrm{H} 3 \mathrm{~N} 2)$ that circulate in the human population also circulate in the swine populations [6]. In addition to the concern for IAV in terms of swine health [7], IAV infection in swine is also important due to the potential for zoonotic infections as well as the potential for serving as a mixing vessel for the generation of human pandemic viruses [5]. The majority of inter-species transmission research has focused on amino acids in the hemagglutinin affecting viral attachment and entry [8]. Although known to be important, other than amino acids associated with temperature sensitivity (e.g., PB2 627 [9] or 701 [10]), the effects of differences in amino acid residues in proteins of the replication complex on species specificity is less well understood. Previous evidence suggests that there may be a role in some of these replication complex proteins in allowing for zoonotic infections [11].

The genome of the enveloped influenza A virion consists of eight segments of negative-sense single-stranded RNA that encode at least ten viral genes: Hemagglutinin (HA), Neuraminidase (NA), Matrix 2 protein (M2), Matrix 1 protein (M1), Non-structural Protein 1 (NS1), Non-structural Protein 2 (NS2), Nucleoprotein (NP), Polymerase Basic 1 (PB-1), Polymerase Basic 2 (PB-2), and Polymerase Acidic (PA) [1]. The viral envelope contains HA, NA, and M2 proteins, and M1 proteins form a layer inside the envelope. The IAV RNA genome located inside the virion is coated with NP and is bound by the replication complex consisting of PB1, PB2, and PA. The NP, the focus of this study, encoded by the fifth IAV RNA segment, binds with high affinity to viral RNA [12]. NP plays a role in viral RNA replication and transcription [12]. More recent data suggests that NP binds the polymerase as well as the newly replicated RNA and may act as a processivity factor that is necessary for replication of the viral RNA to be completed [13]. Phylogenic analysis of IAV NP shows distinct lineages of NP based on the host species [14,15]. Within the NP, there are amino acid signatures found within different host species [16,17]. These host-specific amino acid residues may result in differences in affinities for the various host proteins with which they interact (e.g., importin $\alpha 1$ [18], F- actin [19], nuclear factor 90 [20], cyclophilin E [21], exportin 1 [22], HMGB1 [23], HMGB2 [23], MxA/Mx1 $[24,25]$, HSP40 [26], karyopherin alpha [27,28], clusterin [29], Raf-2p48/BAT1/UAP56 [30], Aly/REF [31], Tat-SF1 [32], TRIM22 [33], and alpha actinin 4 [34]) or they may result in differences in how the NP interacts with other viral proteins that have also made host-specific adaptations [11]. Given the suggestion that NP plays a role in determining host range [5,35-37], it is important to identify all host proteins that interact with NP.

Replication of the IAV is dependent on the host cell machinery and interactions between host proteins and viral proteins. Therefore any inquiry attempting to investigate the life cycle of IAV must incorporate host-pathogen protein interactions in order to truly provide a mechanistic understanding of the process. Previous screens have identified important protein-protein interactions between IAV and host proteins, but often results are not consistent between screens. Therefore, corroborating evidence with additional screens is crucial to accumulating the best understanding of critical pathogen-host interactions in viral replication. As examples, several genome-wide screens have been performed using RNAi to systematically knockdown host genes and evaluate the effect on various stages of the IAV life cycle [38-41]. An integrated approach carried out by Shapira and colleagues involved transcription profiling and yeast two hybrid screens using specific viral proteins as baits [28]. Proteomics approaches have revealed host proteins found within viral particles [42,43]. The Random Homozygous Gene Perturbation strategy was used to identify host factors that prevent influenza-mediated killing of host cells [44].

In order to better understand the role of NP-host protein interactions in IAV replication, a Gal4-based yeast two-hybrid $(\mathrm{Y} 2 \mathrm{H})$ assay was used in this study. The $\mathrm{Y} 2 \mathrm{H}$ system allows for the identification of unique human binding partners with NP. A "bait" plasmid encoding the binding domain (BD) of the Gal4 transcriptional activator fused to NP and a "prey" plasmid encoding Gal4's activation domain (AD) fused to a protein encoded by a human cDNA are introduced into a yeast strain containing Gal4responsive reporter genes. Interaction of the bait and prey brings together Gal4's BD and AD, resulting in transcriptional activation of reporter genes [45]. The $\mathrm{Y} 2 \mathrm{H}$ approach has successfully identified cellular factors (e.g., Raf-2p48/ BAT1/UAP56, Hsp40, KPNA1, KNPA3, KPNA6, C16or f45, GMCL1, MAGED1, MLH1, USHBP1, ZBTB25, CLU, Aly/REF, and ACTN4) that interact with the IAV NP [26-31,34], (Table 1). In this study, the nucleoprotein from a classical swine H1N1 IAV (Sw/NC/44173/00) was used as the "bait" in a Y2H screen against a "prey" HeLa cDNA library. To investigate if the origin of NP affects the ability of the interactions to take place, the nucleoprotein from a contemporary human H3N2 IAV $(\mathrm{A} / \mathrm{Ca} / 07 / 04)$ was also used as the "bait" in a $\mathrm{Y} 2 \mathrm{H}$ screen against the same prey HeLa cDNA library. By determination of the putative interaction partners between NP and human proteins, the possible functions of the newfound protein-protein interactions or verification and perhaps elucidation of previously identified host factors may be further investigated.

Reported herein are ten potential human host cell proteins that interact with IAV NP in a Y2H screen. The 


\begin{tabular}{|c|c|c|c|c|c|}
\hline Gene & Protein description & Complete ORF & Number of prey clones & Prey clones & Previous reports with IAV \\
\hline PAICS & $\begin{array}{l}\text { Phosphoribosylaminoimidazole } \\
\text { carboxylase }\end{array}$ & Yes & 3 & R3, R9, R15 & $\begin{array}{l}\text { Karlas et al. [40], Kumar and } \\
\text { Nanduri [47], Kroeker et al. [48] }\end{array}$ \\
\hline MSANTD3 & $\begin{array}{l}\text { Myb/SANT-like DNA-binding domain } \\
\text { containing } 3\end{array}$ & No & 3 & $\mathrm{R} 10, \mathrm{R} 13, \mathrm{R} 27$ & $\mathrm{~N} / \mathrm{A}$ \\
\hline FLJ30306 & $\begin{array}{l}\text { PREDICTED: Homo sapiens } \\
\text { uncharacterized LOC101059922, mRNA }\end{array}$ & Yes & 2 & R23, R33 & N/A \\
\hline PA28B & Proteasome activator subunit 2 & Yes & 2 & $\mathrm{R} 6, \mathrm{R} 19$ & N/A \\
\hline KCTD9 & $\begin{array}{l}\text { Potassium channel tetramerisation } \\
\text { domain containing } 9\end{array}$ & No & 2 & R34, R36 & $\mathrm{N} / \mathrm{A}$ \\
\hline ACOT13 & Acyl-CoA thioesterase 13 & Yes & 1 & R11 & N/A \\
\hline TRA2B & $\begin{array}{l}\text { Transformer } 2 \text { beta homolog } \\
\text { (Drosophila) }\end{array}$ & Yes & 1 & $\mathrm{R} 12$ & Zhu et al. [56] \\
\hline SLC30A9 & $\begin{array}{l}\text { Solute carrier family } 30 \text { (zinc } \\
\text { transporter), member } 9\end{array}$ & No & 1 & R28 & $\begin{array}{l}\text { Kumar and Nanduri [47], } \\
\text { Sui et al. [44] }\end{array}$ \\
\hline ATP1B1 & $\begin{array}{l}\text { ATPase, } \mathrm{Na}+/ \mathrm{K}+\text { transporting, beta } 1 \\
\text { polypeptide }\end{array}$ & No & 1 & R7 & Mi et al. [51], Liu et al. [50] \\
\hline CKAP5 & Cytoskeleton associated protein 5 & No & 1 & R29 & N/A \\
\hline \multicolumn{6}{|c|}{ Host proteins identified as interacting with IAV nucleoprotein in previously published yeast two-hybrid screens } \\
\hline BAT1/UAP56 & RNA-dependent ATPase & N/A & N/A & N/A & Momose et al. [30] \\
\hline HSP40 & Heat shock protein 40 & N/A & N/A & N/A & Sharma et al. [26] \\
\hline $\begin{array}{l}\text { NPI-1/ SRP1/ } \\
\text { KPNA1 }\end{array}$ & Karyopherin a1 & N/A & N/A & N/A & $\begin{array}{l}\text { O'Neill and Palese [27], } \\
\text { Shapira et al. [28] }\end{array}$ \\
\hline KPNA3 & Karyopherin a3 & N/A & N/A & N/A & Shapira et al. [28] \\
\hline KPNA6 & Karyopherin a6 & $\mathrm{N} / \mathrm{A}$ & N/A & N/A & Shapira et al. [28] \\
\hline C16orf45 & - & $\mathrm{N} / \mathrm{A}$ & N/A & $\mathrm{N} / \mathrm{A}$ & Shapira et al. [28] \\
\hline GMCL1 & $\begin{array}{l}\text { Germ cell-less, spermatogenesis } \\
\text { associated } 1\end{array}$ & N/A & N/A & $\mathrm{N} / \mathrm{A}$ & Shapira et al. [28] \\
\hline MAGED1 & Melanoma antigen family D.1 & $\mathrm{N} / \mathrm{A}$ & N/A & $\mathrm{N} / \mathrm{A}$ & Shapira et al. [28] \\
\hline MLH1 & MutL homolog 1 & N/A & N/A & $\mathrm{N} / \mathrm{A}$ & Shapira et al. [28] \\
\hline USHBP1 & Usher syndrome $1 \mathrm{C}$ binding protein 1 & N/A & N/A & N/A & Shapira et al. [28] \\
\hline ZBTB25 & $\begin{array}{l}\text { Zinc finger and BTB domain } \\
\text { containing } 25\end{array}$ & N/A & N/A & N/A & Shapira et al. [28] \\
\hline CLU & Clusterin & N/A & N/A & N/A & Tripathi et al. [29] \\
\hline ALY/REF & RNA export adaptor protein & $\mathrm{N} / \mathrm{A}$ & N/A & N/A & Balasubramaniam et al. [31] \\
\hline ACTN4 & Alpha-actinin 4 & $\mathrm{~N} / \mathrm{A}$ & N/A & $\mathrm{N} / \mathrm{A}$ & Sharma et al. [34] \\
\hline
\end{tabular}

relative strengths of these protein-protein interactions were characterized by a plating assay and beta-galacto sidase assay.

\section{Results}

\section{Constructing an NP bait and screening a human CDNA prey library}

The nucleoprotein open reading frame from the classical swine IAV H1N1 strain A/Sw/NC/44173/00 and contemporary human IAV H3N2 strain A/Ca/07/04 encode proteins with $89.1 \%$ identity and $94.8 \%$ similarity (Figure 1 ). Of the 49 amino acids that differ between the swine and human NPs, 29 are conservative differences. However, it is worth noting that several of these amino acid differences are signatures that differ between avian, swine and human isolates [16,17]. The two NP ORFs were amplified by PCR, and the resulting PCR products were separately inserted by recombination cloning into $\mathrm{Y} 2 \mathrm{H}$ bait vector pGBKT7 as a C-terminal fusion with Gal4p's DNA binding domain. Correct constructs were confirmed by DNA sequence analysis. Gal4(BD)-NP fusion proteins isolated from yeast cells were detected as $77 \mathrm{KDa}$ bands on a Western blot probed with an anti-Myc antibody (data not shown). When introduced alone into yeast Y2HGold cells, 


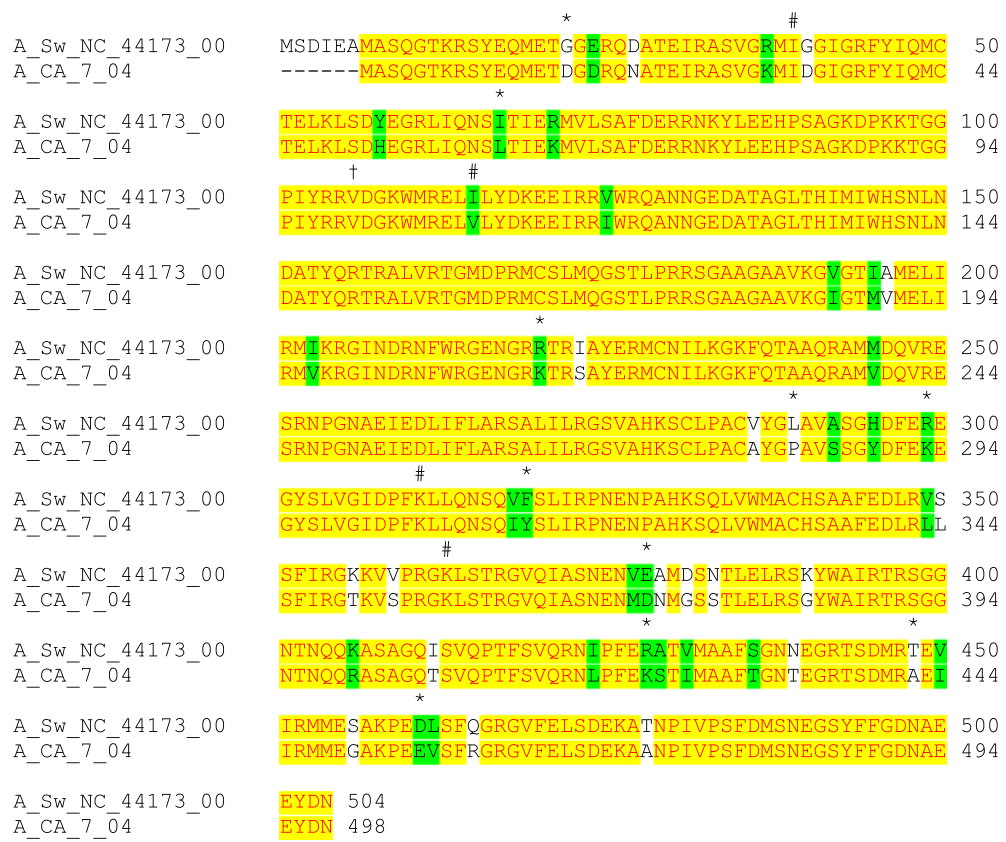

Figure 1 Sequence alignment of nucleoproteins from swine and human influenza A virus strains. The swine and human NPs are $89.1 \%$ identical (yellow highlighting) and $94.8 \%$ similar (yellow and green highlighting). Nonconservative amino acids differences are represented in white. Amino acids with * represent signature amino acids associated with avian influenza A NP, and \# and † represent signature amino acids associated with avian influenza A NP based on Chen et al. [16] and Pan et al. [17]. † Denotes the only deviation of A/Sw/NC 44173/00 from the consensus swine residues based on Pan et al. [17].

the swine and human NP baits constructs were not toxic to yeast and did not autoactivate the $\mathrm{Y} 2 \mathrm{H}$ reporter genes, indicating they were suitable for use in a $\mathrm{Y} 2 \mathrm{H}$ screen (data not shown).

Using a $\mathrm{Y} 2 \mathrm{H}$ assay with Gal4 (BD)-swine NP as a bait and a human HeLa cDNA prey library, approximately $2 \times 10^{6}$ clones were screened resulting in 17 positive bait-prey interacting yeast strains. Sequence and bioinformatics analysis of the prey plasmids indicated that these 17 prey plasmids, listed by their initial positive interaction identification number (R3, R6, etc.), represent ten different human cDNAs (Table 1). An independent screen using Gal4 (BD)-human NP as a bait and a human HeLa cDNA prey library yielded a subset of these same host protein targets. Some of the identified clones contain partial cDNAs. Three independent prey plasmids isolated contained human cDNAs phosphoribosylaminoimidazole carboxylase, phosphoribosylaminoimidazole succinocarboxamide synthetase (PAICS) and another three contained Myb/SANT-like DNA-binding domain containing 3 (MSANTD3). Two independent prey plasmids were isolated for each of three human cDNAs: proteasome activator subunit 2 (PA28B), potassium channel tetramerisation domain (KCTD9), and an uncharacterized protein (FLJ30306). Each of the remaining five prey plasmids contained different human cDNAs.

\section{Evaluation of the strength of bait-prey interactions}

The strength of interaction between each NP bait (swine or human) and human prey in yeast was measured using a qualitative growth assay and a quantitative $\beta$-galactosidase activity assay. First, yeast growth on selective media after cotransformation with swine or human NP and one of the identified prey was tested at both $30^{\circ} \mathrm{C}$ and $37^{\circ} \mathrm{C}$ as a qualitative metric of the protein-protein interaction's strength (Figure 2, Table 2). All strains, including the positive and negative controls, grew on SD-Leu-Trp which selects for the presence of both bait and prey plasmids. Most strains showed decreased growth at $37^{\circ} \mathrm{C}$ relative to the more permissive temperature $30^{\circ} \mathrm{C}$. Strains examined at $37^{\circ} \mathrm{C}$ which contained either swine or human NP bait grew best in the presence of prey CKAP5, MSANTD3, or TRA2B. In contrast, at $37^{\circ} \mathrm{C}$ strains containing swine NP grew poorly with prey ACOT13, whereas strains containing human NP grew poorly with prey PA28B.

The strength of the interactions between IAV NP and host proteins identified by the library screen was also investigated by measuring the $\beta$-gal activity in liquid yeast cultures (Figure 3, Table 2). As observed with the qualitative growth assay, for all ten prey proteins, interactions were observed with both the swine and human NP. Of the ten interactions investigated, yeast strains containing swine or human NP and human prey SLC30A9 and CKAP3 showed 


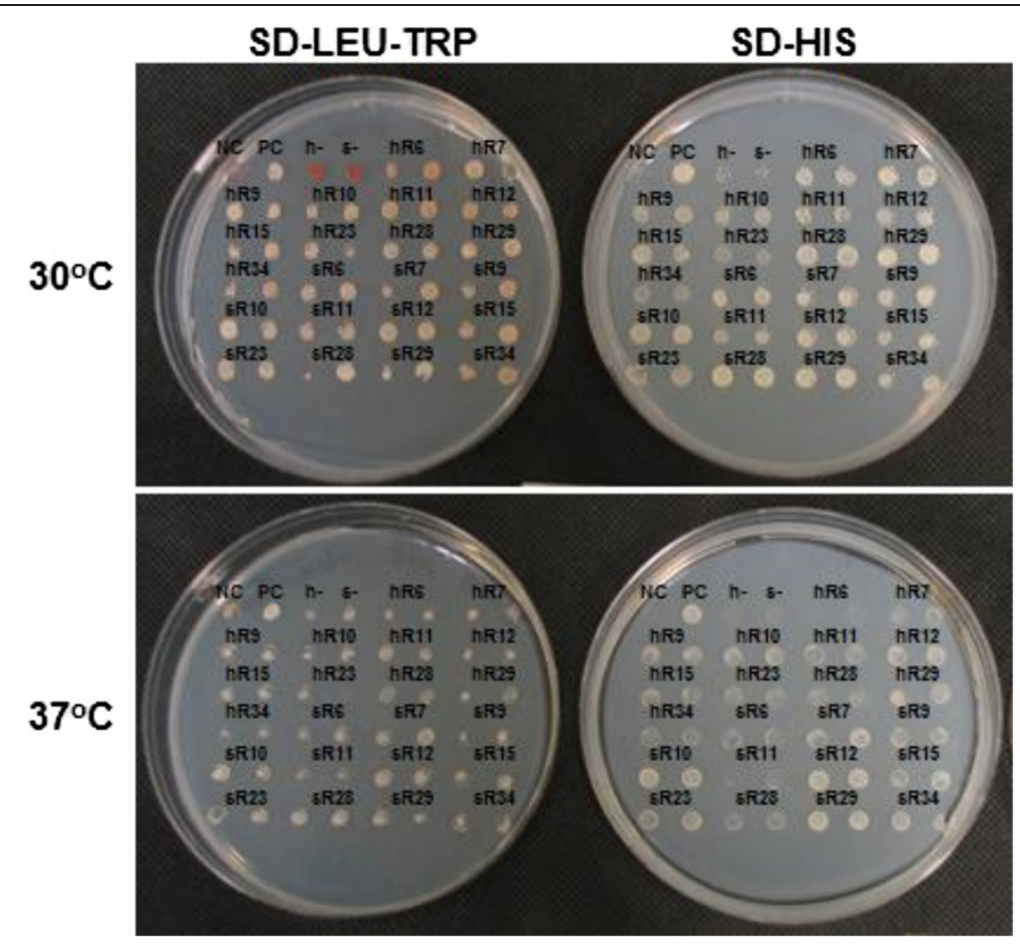

Figure 2 Maintenance of protein-protein interactions at $30^{\circ} \mathrm{C}$ and $37^{\circ} \mathrm{C}$. Yeast cells containing both a bait plasmid and prey plasmid were spotted in duplicate onto agar plates and incubated at $30^{\circ} \mathrm{C}$ or $37^{\circ} \mathrm{C}$. SD-Leu-Trp media serves as a growth control, and SD-His is protein interaction reporter media. Growth on SD-His is represented as normal growth (++), reduced growth (+), and no growth (-) (see Table 2). NC and PC represent negative and positive controls, respectively. Additional yeast strain negative controls include h- (human NP bait and empty prey vector) and s-

(swine NP bait and empty prey vector).

the highest levels of $\beta$-gal activity compared to the other prey proteins examined. This is consistent with the growth of yeast strains containing human NP and SLC30A9 and CKAP3 on selective media at $37^{\circ} \mathrm{C}$ ( Figure 2, Table 2). Even strains with the lowest levels of $\beta$-gal activity observed
(TRA2B and ATP1B1) have double the $\beta$-gal activity of the negative control. While the data suggest there may be differences in the strength of bait-prey interactions based on NP host origin, these differences should be interpreted carefully given the nature of the assay.

Table 2 Summary of affinity of bait-prey interactions

\begin{tabular}{|c|c|c|c|c|c|c|c|c|}
\hline \multirow[b]{2}{*}{ Gene } & \multirow[b]{2}{*}{ Protein description } & \multirow[b]{2}{*}{$\begin{array}{l}\text { Prey } \\
\text { clone }\end{array}$} & \multicolumn{4}{|c|}{ Growth on SD-His agar plates* } & \multicolumn{2}{|c|}{$\beta$-Gal activity** } \\
\hline & & & $\begin{array}{c}\text { Human } \\
\left(30^{\circ} \mathrm{C}\right)\end{array}$ & $\begin{array}{l}\text { Human } \\
\left(37^{\circ} \mathrm{C}\right)\end{array}$ & $\begin{array}{l}\text { Swine } \\
\left(30^{\circ} \mathrm{C}\right)\end{array}$ & $\begin{array}{l}\text { Swine } \\
\left(37^{\circ} \mathrm{C}\right)\end{array}$ & $\begin{array}{c}\text { Human } \\
\text { NP }\end{array}$ & $\begin{array}{l}\text { Swine } \\
\text { NP }\end{array}$ \\
\hline PAICS & Phosphoribosylaminoimidazole carboxylase & R15 & $(++)$ & $(+)$ & $(++)$ & $(++)$ & 2.2 & 30.4 \\
\hline MSANTD3 & Myb/SANT-like DNA-binding domain containing 3 & R10 & $(++)$ & $(++)$ & $(++)$ & $(++)$ & 13.9 & 18.2 \\
\hline FLJ30306 & $\begin{array}{l}\text { PREDICTED: Homo sapiens uncharacterized } \\
\text { LOC101059922, mRNA }\end{array}$ & R23 & $(+)$ & $(+)$ & $(++)$ & $(++)$ & 1.9 & 5.4 \\
\hline PA28B & Proteasome (prosome, macropain) activator subunit 2 & R6 & $(++)$ & $(-)$ & $(++)$ & $(+)$ & 6.7 & 33.3 \\
\hline KCTD9 & $\begin{array}{l}\text { Potassium channel tetramerisation domain } \\
\text { containing } 9\end{array}$ & R34 & $(+)$ & $(+)$ & $(++)$ & $(++)$ & 5.0 & 16.4 \\
\hline ACOT13 & Acyl-CoA thioesterase 13 & R11 & $(++)$ & $(+)$ & $(++)$ & $(-)$ & 6.9 & 15.5 \\
\hline TRA2B & Transformer 2 beta homolog (Drosophila) & $\mathrm{R} 12$ & $(++)$ & $(++)$ & $(++)$ & $(++)$ & 1.9 & 0.85 \\
\hline SLC30A9 & Solute carrier family 30 (zinc transporter), member 9 & R28 & $(++)$ & $(+)$ & $(++)$ & $(+)$ & 82.9 & 119.9 \\
\hline ATP1B1 & ATPase, $\mathrm{Na}+/ \mathrm{K}+$ transporting, beta 1 polypeptide & R7 & $(++)$ & $(+)$ & $(++)$ & $(++)$ & 3.4 & 4.3 \\
\hline CKAP5 & Cytoskeleton associated protein 5 & R29 & $(++)$ & $(++)$ & $(++)$ & $(++)$ & 70.1 & 90.3 \\
\hline
\end{tabular}

* Results from growth on SD-His protein interaction assay media are presented as: (++) normal growth, (+) reduced growth, and (-) no growth (Figure 2).

** Mean $\beta$-galalactosidase activity from at least eight replicates reported in Miller units (Figure 3). 


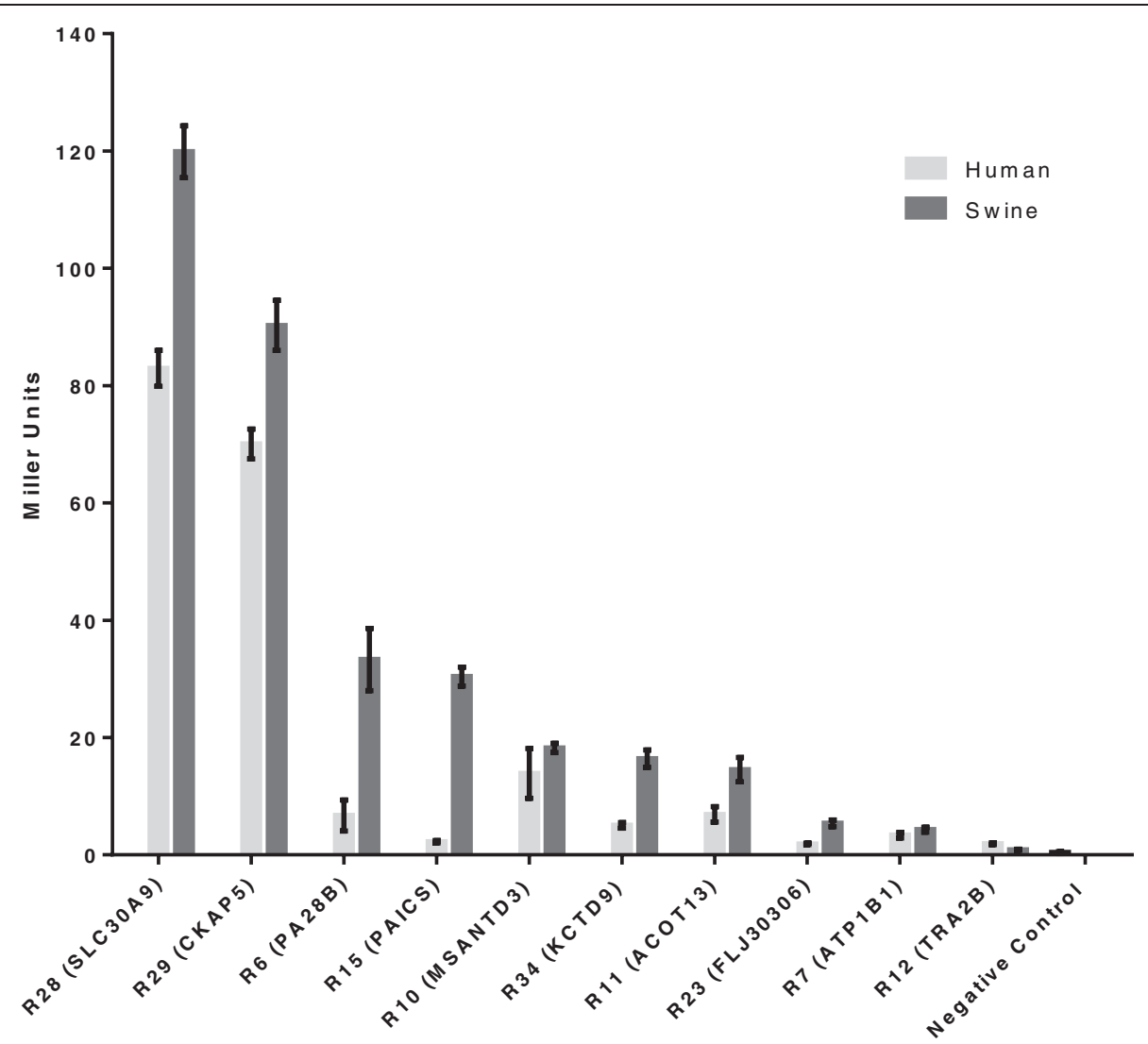

Figure 3 -galactosidase activity in liquid culture. B-gal activity is a quantitative measure of the strength of interaction between bait swine or human NP and prey human host proteins identified in the $\mathrm{Y} 2 \mathrm{H}$ screen. The $\beta$-gal activity for each interacting bait-prey pair is expressed in Miller units and represents the mean and standard error of the mean of at least eight independent samples.

\section{Discussion}

This $\mathrm{Y} 2 \mathrm{H}$ screen identified multiple candidate host proteins that were previously identified in genome-wide screens as playing a role in the IAV infection cycle (PAICS, ATP1B1, SLC30A9, and TRA2B), while also identifying new potential interactors with IAV nucleoprotein (ACOT13, CKAP5, KCTD9, PA28B, MSANDTD3, and FLJ30306). These results complement previous reports by suggesting the mechanism for involvement of the host proteins with the IAV (i.e. interaction with the NP). The yeast screen is internally validated by the observation that half of the prey proteins identified were independently isolated multiple times during the screen. All host prey proteins identified interact in yeast with IAV NP from both human and swine isolates. Although there can be variability in gene expression among yeast colonies containing the same combination of bait/prey, both a qualitative growth assay and a quantitative $\beta$-gal assay yielded similar results in terms of the strength of interaction between IAV NP bait and human prey proteins. Notably, CKAP5 displayed good growth at the more stringent $37^{\circ} \mathrm{C}$ in the qualitative assay and also had high $\beta$-gal activity. The putative interacting host proteins represent a variety of cellular processes, consistent with the diversity of processes required during the IAV infection cycle.

Phosphoribosylaminoimidazole carboxylase, phosphoribosylaminoimidazole succinocarboxamide synthetase (PAICS) is an enzyme necessary to catalyze the sixth and seventh steps of the de novo purine biosynthesis pathway [46]. PAICS has been identified by two separate RNAi screens as being crucial to IAV replication [40,47]. Furthermore, proteins involved in purine biosynthesis, including PAICS, were found to be significantly up-regulated during an IAV infection [48]. The data presented herein suggest that the requirement for PAICS during IAV infection may be through the interaction with NP.

The sodium/potassium-transporting ATPase subunit beta-1 (ATP1B1) represents another host protein that interacts in yeast with NP and that has been previously shown to be important for influenza virus replication in host cells. It belongs to the family of $\mathrm{Na}+/ \mathrm{K}+-$ ATPase beta chain proteins. $\mathrm{Na}+/ \mathrm{K}+-$ ATPase is necessary for the creation and maintenance of electrochemical gradients of sodium and potassium ions on either side of the plasma membrane [49]. This gradient is used by cells to permit functional nervous and muscular excitability, osmoregulation, and active 
transport of numerous molecules [49]. The beta subunit functions to regulate the quantity of sodium pumps transported to the plasma membrane [49]. Using a quantitative proteomics approach, ATP1B1 was one of 43 proteins found to be significantly up-regulated in IAV-infected primary human alveolar macrophages [50]. In a $\mathrm{Y} 2 \mathrm{H}$ study, $\mathrm{Mi}$ and colleagues [51] isolated ATP1B1 as a protein that binds the cytoplasmic domain of IAV M2 and subsequently showed that knockdown of ATP1B1 in MDCK cells suppressed IAV replication [51]. These studies suggest that ATP1B1 may be interacting with multiple IAV proteins.

The solute carrier family 30 (zinc transporter), member 9 (SLC30A9) is involved in nucleotide-excision repair of human DNA [52] and has an efflux motif characteristic of proteins in the SLC30 zinc efflux transporter family [53]. SLC30A9 protein found in the cytoplasm can bind nuclear receptors and/or nuclear receptor coactivators and translocate to the nucleus where it regulates gene transcription [54]. SLC30A9 was identified as a possible host target that confers upon the host cell resistance to IAV infection [44]. How SLC30A9 might interact with NP and be necessary for IAV replication is unclear.

Another protein identified by this screen is TRA2B, a tissue-specific splicing factor [55]. TRA2B protein binds to AGAA and CAA RNA sequences affecting the inclusion of introns in the processed transcript [55]. With respect to influenza, expression of TRA2B protein was reported to be down-regulated in porcine alveolar macrophage cells infected by two swine IAVs [56]. Because influenza genes M2 and NS2 are spliced, it is possible that TRA2B is important for the splicing of these genes. However, how NP might be involved in TRA2B's function in IAV replication is unknown.

Another binding partner identified is Acyl CoA thioesterase 13 (ACOT13), a eukaryotic protein also known as thioesterase superfamily member 2 (Them2) [57,58]. ACOT13 catalyzes fatty acyl-CoA hydrolysis that exists primarily in association with mitochondria [57]. ACOT13/ Them2 was identified in a $\mathrm{Y} 2 \mathrm{H}$ screen focused on phosphatidylcholine transfer protein, suggestive of a role in fatty acid metabolism [57]. Although ACOT13 has not previously been reported to play a role in the IAV life cycle, another member of the ACOT family (ACOT9) which has two hot dog fold domains (ACOT13 has one) [59] has been shown to physically interact with the IAV PA protein [28]. How ACOT13 may be interacting with NP during IAV replication is unclear.

Cytoskeletal associated protein 5 (CKAP5, also known as TOG) binds microtubules and is important for the process of centrosomal microtubule assembly especially during mitosis [60]. The microtubule network of the cell plays a role in movement of materials throughout the cell, including during infection [61]. TOG2 binds to a ribonucleoprotein and plays a role in RNA trafficking [62]. While a specific role for CKAP5 in the IAV life cycle is unknown, a genome-wide siRNA screen revealed CKAP5 as one of 96 human genes that supports replication of another RNA virus- the hepatitis $C$ virus [63]. It's possible that CKAP5 functions during the IAV infection cycle to organize microtubules for trafficking of viral components.

Another interactor identified in this screen, KCTD9, has been previously shown to interact with a subunit of the Mediator complex, acting as a scaffold between regulatory proteins and the RNA polymerase II [64]. In addition, KCTD9 homolog FIP2 acts as a cytoskeletal rearrangement protein suspected to be involved in nuclear export in some plants through the organization of actin cables [64]. Perhaps KCTD9 aids in translocating NP to the nucleus for replication and transcription of the viral RNA. It has been shown that the translocation of NF-E2 related factor 2 (Nrf2) is mediated by cytoskeletal rearrangement in the oxidative stress response [65], and the level of Nrf2 expression is associated with IAV entry and replication in nasal epithelial cells [66].

Also identified by this screen was PA28B, a protein associated with the proteasome complex. In the typical proteasome, there is a $19 \mathrm{~S}$ regulator, which is replaced by the $11 \mathrm{~S}$ regulator in the modified immunoproteasome [67]. PA28B is part of the proteasome complex and acts as a subunit in the $11 \mathrm{~S}$ alternate regulator. It is referred to as the beta subunit and is comprised of three beta and three alpha subunits arranged in a heterohexameric ring [68]. The proteasome, as a whole, is used for the cleaving of peptides and the $11 \mathrm{~S}$ regulator, in particular, induces the degradation of short peptides, but not entire proteins [68]. Induction of $11 \mathrm{~S}$ regulator expression is the responsibility of interferon gamma. PA28B is involved in cleavage of the peptides which bind to the major histocompatibility complex (MHC). It is possible that NP interacts with PA28B to prevent MHC I presentation of IAV antigens.

Myb/SANT-like DNA-binding domain containing 3 (MSANTD3) is a member of the MSANTD3 family which contains DNA binding domains for Myb proteins and the SANT domain family. Myb proteins are proto-oncogenes which are necessary for hematopoiesis and possibly involved in tumorigenesis [69]. The SANT domain permits the interaction of chromatin remodeling proteins with histones and is found in chromatin-remodeling complexes as well as nuclear receptor co-repressors [70]. NP interactions with MSANTD3 could have an effect on gene transcription of the host through chromatin modification, presumably to inhibit antiviral genes or up-regulate genes beneficial to viral replication.

The screen also identified FLJ30306 as a potential interactor with NP. FLJ30306 maintains a sequence similarity to retroviral elements, resulting in its classification as endogenous retrovirus group $\mathrm{K} 3$, member 1 [Homo sapiens] 
[71]. The endogenous retrovirus sequence was revealed by sequence analysis of the mRNA, not by direct protein sequencing. It is unclear whether the protein carries out a normal cellular effect, such as endogenous retrovirus 1's (ERV-1) use in placental syncytia formation or if it is a result of mis-regulation due to influenza infection [71]. In Hodgkin's lymphoma it has been shown that many endogenous retroviruses are reactivated and produce virus-like particles [71]. It may be that instead of directly utilizing FLJ30306 influenza may simply be up-regulating its expression due to its pathogenesis. Alternatively, FLJ30306 may contain useful enzymatic activity for influenza replication through an unknown mechanism. A characterization of normal FLJ30306 function would allow for appropriately testing either hypothesis.

All human host proteins identified in this $\mathrm{Y} 2 \mathrm{H}$ screen interact in yeast with NP from both swine and human IAV strains. While the data suggest there may be differences in the strength of bait-prey interactions in yeast based on NP host origin, these differences should be interpreted carefully given the nature of the assay. Given the suggestion that NP affects species specificity, additional screens using NP from other IAV strains as the bait and/or cDNA libraries from other susceptible species may shed light on amino acids within the NP and specific host factors that are responsible for host restrictions. As is the case with other published screens (e.g., [72]), it will be important to verify the putative interactions described here in infected cells by co-immunoprecipitation, co-localization, or RNA interference (e.g., [34]) and to investigate the role of the identified host proteins in the IAV life cycle.

\section{Conclusions}

A Y2H screen using a classical swine influenza A virus nucleoprotein as a bait resulted in isolation of ten different putative interacting human host proteins involved in a variety of cellular processes and structures: purine biosynthesis (PAICS), metabolism (ACOT13), proteasome (PA28B), DNA-binding (MSANTD3), cytoskeleton (CKAP5), potassium channel formation (KCTD9), zinc transporter function (SLC30A9), $\mathrm{Na}+/ \mathrm{K}+$ ATPase function (ATP1B1), and RNA splicing (TRA2B). All of the identified human host proteins interacted in yeast with NP from both human and swine origin. Proteins PAICS, ATP1B1, TRA2B, and SLC30A9 have been previously identified in studies related to host response to the IAV. Host proteins SLC30A9 and CKAP5 displayed the strongest interactions with IAV NP in yeast in a quantitative $\beta$-gal assay.

\section{Methods}

Strains, plasmids, media, microbial growth conditions, and reagents

Unless indicated otherwise, yeast strains (Table 3) were grown in liquid culture at $30^{\circ} \mathrm{C}$ at $180 \mathrm{rpm}$ and on agar plates at $30^{\circ} \mathrm{C}$. Bacterial strains were grown in liquid culture at $37^{\circ} \mathrm{C}$ at $200 \mathrm{rpm}$ and on agar plates at $37^{\circ} \mathrm{C}$. Selectable markers for the bait (pGBKT7) and prey (pGADT7) plasmids in the yeast Saccharomyces cerevisiae and bacterium E. coli are listed in Table 3. All media and $\mathrm{Y} 2 \mathrm{H}$ reagents were purchased from Clontech (Mountain View, CA).

\section{Cloning Influenza A virus nucleoprotein into vector pGBKT7}

The open reading frame (ORF) of the nucleoprotein gene from swine IAV $\mathrm{H} 1 \mathrm{~N} 1$ strain $\mathrm{A} / \mathrm{Sw} / \mathrm{NC} / 44173 / 00$ was amplified from the plasmid pScript A/Sw/NC/44173/00 NP (a gift from Christopher Olsen) by PCR using forward primer NP3F 5'-CATGGAGGCCGAATTCatggcgtctcaaggcaccaaacga-3' and reverse primer NP2R 5'-GCAGGTCGACGGATCCattgtcatactcctctgcattgtctccgaaga-3'. The NP ORF from the human IAV H3N2 strain $\mathrm{A} / \mathrm{Ca} / 07 / 04$ was amplified from plasmid pScript A/Ca/07/04 NP (a gift from Christopher Olsen) by PCR using forward primer NP2F 5'-CATGGAGGCCGAATTC atggcgtcccaaggcacca aacg-3' and reverse primer NP3R 5'-GCAGGTCGACG GATCC attgtcgtactcttctgcattgtctccgaaga-3'. For all primers the uppercase letters represent sequences homologous to the BamHI-EcoRI-linearized vector pGBKT7, and lower case letters represent sequences specific for the NP ORF. Reactions included $200 \mathrm{ng}$ plasmid template DNA, 1X Advantage HD Buffer (Clontech, Mountain View, CA), $0.2 \mathrm{mM}$ dNTPs, $0.25 \mu \mathrm{M}$ forward and reverse primers, and 0.625 Units Advantage HD Polymerase (Clontech, Mountain View, CA). Thermocycler conditions were as follows: $95^{\circ} \mathrm{C}$ for 3 minutes; 30 cycles of $\left[95^{\circ} \mathrm{C}\right.$ for 15 seconds, $55^{\circ} \mathrm{C}$ for 5 seconds, $72^{\circ} \mathrm{C}$ for 100 seconds], $72^{\circ} \mathrm{C}$ for 10 minutes.

InFusion cloning (Clontech, Mountain View, CA) was used to insert the NP ORFs into BamHI-EcoRI-linearized pGBKT7 3' and in-frame with DNA encoding Gal4's DNA binding domain (BD). Conditions were as follows: $60 \mathrm{ng}$ gel-purified BamHI-EcoRI-linearized pGBKT7, 50 ng gelpurified NP PCR product, and $1 \mathrm{X}$ InFusion HD Enzyme Premix in a $5 \mu \mathrm{l}$ reaction were incubated at $50^{\circ} \mathrm{C}$ for $15 \mathrm{~min}$. An aliquot of the cloning reaction was transformed into Stellar competent cells per the manufacturer's directions (Clontech, Mountain View, CA). All plasmid sequences were verified by DNA sequencing.

\section{Yeast two-hybrid screen}

The Yeast Two-Hybrid MatchMaker Gold system (Clontech, Mountain View, CA) was used to isolate prey plasmids that interact with bait pGBKT7-NP. A $50 \mathrm{ml}$ SD-TRP liquid media culture inoculated with Y2HGold cells containing the bait plasmid pGBKT7-NP was grown in a $200 \mathrm{rpm}$ shaker at 30 degrees to an OD600 of 0.8 (approximately 18 hours). Bait cells were pelleted by centrifugation, resuspended in $4 \mathrm{ml}$ SD-TRP, and mixed with $45 \mathrm{ml}$ YPDA in a $2 \mathrm{~L}$ flask with $2 \times 10^{7}$ 
Table 3 Strains and plasmids

\begin{tabular}{lll}
\hline Yeast strain & Genotype & Reporter genes \\
\hline Y2HGold & MATa, trp1-901, leu2-3, 112, ura3-52, his3-200, gal4A, gal804, & ADE2, HIS3, MEL1, AUR1-C \\
& LYS2::GAL1UAS-Gal1TATA-His3, GAL2UAS-Gal2TATA-Ade2 & \\
& URA3::MELIUAS-Mel1TATA, AUR1-C MEL1 \\
& ade2-101, trp1-901, leu2-3, 112, gal44, gal804, met-, & MEL1, LacZ \\
YRA3::GAL1UAS-Gal1TATA-LaCZ, MEL1 & \\
\hline Plasmid & Selectable markers (yeast, bacteria) & Additional information \\
\hline Plasmid pGBKT7 (bait vector) & TRP1, Kan & GAL4(1-147)DNA-BD, TRP1, kanr, C-Myc epitope tag \\
Plasmid pGADT7 (prey vector) & LEU2, Amp & GAL4(768-881)AD, LEU2, ampr, HA epitope tag \\
\hline
\end{tabular}

Y187 cells containing a commercially-available normalized HeLa S3 Mate and Plate cDNA prey library (Clontech, Mountain View, CA). Bait and prey cells were mated by slow shaking $(40 \mathrm{rpm})$ for 24 hours at $30^{\circ} \mathrm{C}$. After 20 hours, mating cells were observed microscopically for the presence of zygotes. Mated cells were centrifuged 1,000 $\times$ g for $10 \mathrm{~min}$, and the pellet was resuspended in $5 \mathrm{ml} 0.5 \mathrm{X}$ YPDA containing $50 \mu \mathrm{g} / \mathrm{ml}$ kanamycin. Mated cells $(0.2 \mathrm{ml})$ were spread on each of 55 SD-LEU-TRP/X-a-Gal/ $125 \mathrm{ng} / \mathrm{ml}$ AbA agar plates, and plates were incubated $30^{\circ} \mathrm{C}$ for $5-8$ days. This concentration of AbA is considered high stringency and could exclude isolation of lowaffinity interactors. The mating efficiency was determined by plating 1:1,000 and 1:10,000 dilutions on SD-LEU, SDTRP, and SD-LEU-TRP agar plates.

Blue colonies from the Y2H screen SD-LEU-TRP/X-a$\mathrm{Gal} / \mathrm{AbA}$ plates were picked as small patches to an SDLEU-TRP plate, grown 2 days at $30^{\circ} \mathrm{C}$, and replica plated to agar media (SD-ADE, SD-HIS, SD-LEU-TRP/X-a-Gal, SD-LEU-TRP/AbA) to test for activation of four reporter genes: $A D E 2, H I S 3, M E L 1 C$, and AUR1-C, respectively. Replica plates were incubated at $30^{\circ} \mathrm{C}$ and observed daily for 3 days. Cells from potential positive interactors (growing on all types of reporter media and blue/light blue on SD-LEU-TRP/X- $\alpha$-Gal) were single-colony purified on SD-LEU-TRP/X-a-Gal and incubated at $30^{\circ} \mathrm{C}$ for 4 days. A single blue colony from each potential positive interaction strain was single-colony purified a second time on SDLEU-TRP/X- $\alpha-$ Gal.

Following two rounds of streaking, the prey plasmid from each potential positive interaction yeast strain was isolated using the "Easy Yeast Plasmid Isolation Kit" (Clontech, Mountain View, CA). The resulting yeast plasmid DNAs were transformed into and subsequently re-isolated from $E$. coli cells.

Testing potential positive prey plasmids for toxicity to yeast and autoactivation of the $\mathrm{Y} 2 \mathrm{H}$ reporter genes

Isolated prey plasmid DNAs were re-introduced into Y2HGold cells using a yeast transformation system (Geno Technology). Y2HGold cells containing prey plasmids were single-colony purified on SD-Leu agar plates alongside a control (Y2HGold containing the empty prey vector pGADT7), and cell growth was observed after 3 days at $30 \mathrm{C}$ to test for toxicity. To test for false positives, patches of Y2HGold cells containing prey plasmids were replica plated to assess autoactivation of reporter genes on reporter media (SD-Ade, SD-His, SD-Leu-Trp + X- $\alpha$-Gal, SD-Leu-Trp + AbA). Prey strains determined to be false positives in yeast were excluded from the pool of identified interacting host proteins.

\section{Bioinformatics}

The 5' and 3' ends of human cDNA within each confirmed positive prey plasmid were determined by sequencing at the Iowa State University (ISU) DNA Facility using primers T7-1 (AATACGACTCACTATAG) and 3'AD (AGATGGTGCACGATGCACAG) or 3' polyTA (TTTTTTTTTTTTTTTTTTTTTTTTTA), respectively. The sequence data was used in a BLAST to query the NCBI human genome and human transcript databases.

\section{Maintenance of protein-protein interactions at $30^{\circ} \mathrm{C}$ and $37^{\circ} \mathrm{C}$}

Y2HGold yeast cells were separately co-transformed with a bait plasmid (either pGBKT7 bait vector containing NP from human influenza A strain $\mathrm{H} 3 \mathrm{~N} 2, \mathrm{~A} / \mathrm{Ca} / 07 / 04$ or $\mathrm{NP}$ from swine influenza A strain H1N1, A/Sw/NC/44173/00) and a prey plasmid (pGADT7 containing one of the human cDNAs isolated as a positive interactor with human NP bait). Y2HGold cells containing known bait/prey interactors pGBKT7-53 and pGADT7-T and known noninteractors pGBKT7-Lam and pGADT7-T were used as positive and negative controls, respectively. Additional negative interaction controls included Y2HGold cells containing human or swine NP (described above) and an empty prey vector pGADT7.

All transformants were grown in YPD media in overnight cultures and were diluted to a concentration of $5 \times 10^{6}$ cells $/ \mathrm{ml}(\mathrm{OD}=0.417) .200 \mathrm{ml}$ of culture was placed into a 96 well plate. A 48 sample pinner was used to spot yeast onto 2 plates each of SD-Leu-Trp (control), and SD-His. One plate of each type was incubated at $30^{\circ} \mathrm{C}$, the other was incubated at $37^{\circ} \mathrm{C}$. Growth was assessed and images taken 4 days after the initial plating procedure. At least two 
replicates of each strain containing the bait (swine NP or human NP) and prey were tested on SD-Leu-Trp and SDHis at both $30^{\circ} \mathrm{C}$ and $37^{\circ} \mathrm{C}$.

\section{B-galactosidase assay}

Diploid cells containing bait and prey were prepared by mating Y187 cells containing each of the prey plasmids with Y2HGold cells containing each of the bait plasmids (swine NP or human NP) on YPD agar (MatchMaker Gold Y2H protocol, Clontech, Mountainview, CA). Eight replicate samples of diploids were selected by subsequent growth on SD-Leu-Trp agar for each protein interaction. Diploid cells containing bait/prey were inoculated in $2 \mathrm{~mL}$ SD-Leu/Trp liquid media and grown in a $200 \mathrm{rpm}$ shaker at $30^{\circ} \mathrm{C}$ overnight. $2 \mathrm{~mL}$ of the overnight cultures were diluted to $4 \mathrm{~mL}$ with YPD media and grown in a $200 \mathrm{rpm}$ shaker at $30^{\circ} \mathrm{C}$ until they reached mid-log phase $\left(\mathrm{OD}_{600}\right.$ of $0.5-0.8$ ). Cultures were separated into $1.5 \mathrm{~mL}$ aliquots, pelleted, washed once, and then resuspended in $300 \mu \mathrm{L}$ of $\mathrm{Z}$ buffer $\left(16.1 \mathrm{~g} / \mathrm{L} \mathrm{Na}_{2} \mathrm{HPO}_{4} \cdot 7 \mathrm{H}_{2} \mathrm{O}, 5.5 \mathrm{~g} / \mathrm{L} \mathrm{NaH} \mathrm{PO}_{4} \cdot \mathrm{H}_{2} \mathrm{O}\right.$, $\left.0.75 \mathrm{~g} / \mathrm{L} \mathrm{KCl}, 0.246 \mathrm{~g} / \mathrm{L} \mathrm{MgSO}_{4} \cdot 7 \mathrm{H}_{2} \mathrm{O}, \mathrm{pH} 7.0\right)$. Samples of $100 \mu \mathrm{L}$ were lysed by three freeze/thaw cycles with liquid nitrogen and a $37^{\circ} \mathrm{C}$ water bath. After the cells were lysed, the sample was split into two $150 \mu \mathrm{L}$ aliquots. A blank tube, containing 100uL of $\mathrm{Z}$ buffer, was also set up. To analyze the enzyme activity, $350 \mu \mathrm{L}$ of $\mathrm{Z}$ buffer with $0.27 \%$ $\beta$-mercaptoethanol and $4 \mathrm{mg} / \mathrm{ml}$ of ONPG as substrate were added. The yellow color was then allowed to develop at $30^{\circ} \mathrm{C}$, and the reaction was stopped by the addition of $200 \mu \mathrm{L}$ of $1 \mathrm{M} \mathrm{Na}_{2} \mathrm{CO}_{3}$. To remove cell debris, the samples were centrifuged for 10 minutes at 16,000 RCF, and $\mathrm{OD}_{420}$ values were recorded. In order to express the enzyme activity, Miller Units were calculated using the formula: $1000 * \mathrm{OD}_{420} /\left(\mathrm{t}^{*} \mathrm{~V}^{*} \mathrm{OD}_{600}\right)$ where $\mathrm{t}$ refers to the elapsed time, and $\mathrm{V}$ refers to the dilution factor $(0.25$ in this case).

\section{Abbreviations \\ Y2H: Yeast two-hybrid; SD-Leu: Synthetic defined media lacking leucine; SD-Trp: Synthetic defined media lacking tryptophan; SD-Leu-Trp: Synthetic defined media lacking leucine and tryptophan; SD-Ade: Synthetic defined media lacking adenine; SD-His: Synthetic defined media lacking histidine; IAV: Influenza A virus; AbA: Aureobasidin A; X-a-Gal: X-alpha galactose: YPDA: Yeast peptone dextrose adenine; amp: Ampicillin; kan: Kanamycin; NP: Nucleoprotein; BD: Binding domain; AD: Activation domain; ONPG: o-nitrophenyl $\beta$-d-glucopyranoside.}

\section{Competing interests}

The authors declare that they have no competing interests.

\section{Authors' contributions}

HS, MB participated in study design; HS with assistance from students constructed the bait plasmid and carried out the $\mathrm{Y} 2 \mathrm{H}$ screen; $\mathrm{AG}, \mathrm{HS}, \mathrm{JB}$, JJ, MT carried out bioinformatics analyses; AG, JB, JJ, MT tested interaction of prey with NP from a human influenza strain; MT, $H S, A G, J B$ carried out the $\beta$-gal assay; AG carried out the plating assay; AG, MT, JB, HS carried out the Western blot; AG, HS, JB, JJ, MB, MT prepared the manuscript. All authors read and approved the manuscript.

\section{Acknowledgements}

We thank Christopher Olsen, University of Wisconsin, for providing the pScript A/Sw/NC/44173/00 NP and pScript A/Ca/07/04 NP plasmids and Bomi Davis, Randi Rumbold, Lauren Reed, and Carolyn Wurzer for constructing the bait plasmids. We also appreciate the efforts of Drake University students who initiated the Y2H screen while enrolled in Drake's Spring 2012 BIO187L course. This work was funded by research grants to MB and HS from NASA-ISGC and Drake University.

Received: 17 June 2014 Accepted: 15 December 2014

Published online: 30 December 2014

\section{References}

1. Taubenberger JK, Morens DM: The pathology of influenza virus infections. Annu Rev Pathol 2008, 3:499-522.

2. Taubenberger JK, Morens, DM: 1918 Influenza: the Mother of All Pandemics. http://wwwnc.cdc.gov/eid/article/12/1/05-0979_article.htm (2006). Accessed 17 June 2014.

3. (CDC) CfDCaP: Swine influenza A (H1N1) infection in two children-Southern California, March-April 2009. MMWR Morb Mortal Wkly Rep 2009, 58:400-402.

4. Dawood FS, Jain S, Finelli L, Shaw MW, Lindstrom S, Garten RJ, Gubareva LV, $\mathrm{Xu}$ X, Bridges CB, Uyeki TM: Emergence of a novel swine-origin influenza A (H1N1) virus in humans. N Engl J Med 2009, 360:2605-2615.

5. Webster RG, Bean WJ, Gorman OT, Chambers TM, Kawaoka Y: Evolution and ecology of influenza A viruses. Microbiol Rev 1992, 56:152-179.

6. Olsen CW: The emergence of novel swine influenza viruses in North America. Virus Res 2002, 85:199-210.

7. Vincent AL, Ma W, Lager KM, Janke BH, Richt JA: Swine influenza viruses a North American perspective. Adv Virus Res 2008, 72:127-154.

8. Skehel JJ, Wiley DC: Receptor binding and membrane fusion in virus entry: the influenza Hemagglutinin. Annu Rev Biochem 2000, 69:531-569.

9. Subbarao EK, London W, Murphy BR: A single amino acid in the PB2 gene of influenza A virus is a determinant of host range. J Virol 1993, 67:1761-1764.

10. Gabriel G, Dauber B, Wolff T, Planz O, Klenk HD, Stech J: The viral polymerase mediates adaptation of an avian influenza virus to a mammalian host. Proc Natl Acad Sci U S A 2005, 102:18590-18595.

11. Manz B, Schwemmle M, Brunotte L: Adaptation of avian influenza A virus polymerase in mammals to overcome the host species barrier. J Virol 2013, 87:7200-7209.

12. Portela A, Digard P: The influenza virus nucleoprotein: a multifunctional RNAbinding protein pivotal to virus replication. J Gen Virol 2002, 83:723-734.

13. Marklund JK, Ye Q, Dong J, Tao YJ, Krug RM: Sequence in the influenza A virus nucleoprotein required for viral polymerase binding and RNA synthesis. J Virol 2012, 86:7292-7297.

14. Scholtissek C, Ludwig S, Fitch WM: Analysis of influenza A virus nucleoproteins for the assessment of molecular genetic mechanisms leading to new phylogenetic virus lineages. Arch Virol 1993, 131:237-250

15. Xu J, Christman MC, Donis RO, Lu G: Evolutionary dynamics of influenza $A$ nucleoprotein (NP) lineages revealed by large-scale sequence analyses. Infect Genet Evol 2011, 11:2125-2132.

16. Chen GW, Chang SC, Mok CK, Lo YL, Kung YN, Huang JH, Shih YH, Wang JY, Chiang C, Chen CJ, Shih SR: Genomic signatures of human versus avian influenza A viruses. Emerg Infect Dis 2006, 12:1353-1360.

17. Pan C, Cheung B, Tan S, Li C, Li L, Liu S, Jiang S: Genomic signature and mutation trend analysis of pandemic (H1N1) 2009 influenza A virus. PLoS One 2010, 5:e9549.

18. Gabriel G, Herwig A, Klenk HD: Interaction of polymerase subunit PB2 and NP with importin alpha1 is a determinant of host range of influenza A virus. PLoS Pathog 2008, 4:e11.

19. Digard P, Elton D, Bishop K, Medcalf E, Weeds A, Pope B: Modulation of nuclear localization of the influenza virus nucleoprotein through interaction with actin filaments. J Virol 1999, 73:2222-2231.

20. Wang P, Song W, Mok BW, Zhao P, Qin K, Lai A, Smith GJ, Zhang J, Lin T, Guan $Y$, Chen $\mathrm{H}$ : Nuclear factor 90 negatively regulates influenza virus replication by interacting with viral nucleoprotein. J Virol 2009, 83:7850-7861.

21. Wang Z, Liu X, Zhao Z, Xu C, Zhang K, Chen C, Sun L, Gao GF, Ye X, Liu W: Cyclophilin $E$ functions as a negative regulator to influenza virus replication by impairing the formation of the viral ribonucleoprotein complex. PLoS One 2011, 6:e22625.

22. Elton D, Simpson-Holley M, Archer K, Medcalf L, Hallam R, McCauley J, Digard P: Interaction of the influenza virus nucleoprotein with the cellular CRM1-mediated nuclear export pathway. J Virol 2001, 75:408-419. 
23. Moisy D, Avilov SV, Jacob Y, Laoide BM, Ge X, Baudin F, Naffakh N, Jestin JL: HMGB1 protein binds to influenza virus nucleoprotein and promotes viral replication. J Virol 2012, 86:9122-9133.

24. Turan K, Mibayashi M, Sugiyama K, Saito S, Numajiri A, Nagata K: Nuclear MxA proteins form a complex with influenza virus NP and inhibit the transcription of the engineered influenza virus genome. Nucleic Acids Res 2004, 32:643-652.

25. Verhelst J, Parthoens E, Schepens B, Fiers W, Saelens X: Interferon-inducible protein $\mathrm{Mx} 1$ inhibits influenza virus by interfering with functional viral ribonucleoprotein complex assembly. J Virol 2012, 86:13445-13455.

26. Sharma K, Tripathi S, Ranjan P, Kumar P, Garten R, Deyde V, Katz JM, Cox NJ, Lal RB, Sambhara S, Lal SK: Influenza A virus nucleoprotein exploits Hsp40 to inhibit PKR activation. PLOS One 2011, 6:e20215.

27. O'Neill RE, Palese P: NPI-1, the human homolog of SRP-1, interacts with influenza virus nucleoprotein. Virology 1995, 206:116-125.

28. Shapira SD, Gat-Viks I, Shum BOV, Dricot A, de Grace MM, Wu L, Gupta PB, Hao T, Silver SJ, Root DE: A physical and regulatory map of host-influenza interactions reveals pathways in H1N1 infection. Cell 2009, 139:1255-1267.

29. Tripathi S, Batra J, Cao W, Sharma K, Patel JR, Ranjan P, Kumar A, Katz JM, Cox NJ, Lal RB, Sambhara S, Lal SK: Influenza A virus nucleoprotein induces apoptosis in human airway epithelial cells: implications of a novel interaction between nucleoprotein and host protein Clusterin. Cell Death Dis 2013, 4:e562. doi:10.1038/cddis.2013.89.

30. Momose F, Basler CF, O'Neill RE, Iwamatsu A, Palese P, Nagata K: Cellular splicing factor RAF-2p48/NPI-5/BAT1/UAP56 interacts with the influenza virus nucleoprotein and enhances viral RNA synthesis. J Virol 2001, 75:1899-1908.

31. Balasubramaniam VR, Hong Wai T, Ario Tejo B, Omar AR, Syed Hassan S: Highly pathogenic avian influenza virus nucleoprotein interacts with TREX complex adaptor protein Aly/REF. PLoS One 2013, 8:e72429.

32. Naito T, Kiyasu Y, Sugiyama K, Kimura A, Nakano R, Matsukage A, Nagata K: An influenza virus replicon system in yeast identified Tat-SF1 as a stimulatory host factor for viral RNA synthesis. Proc Natl Acad Sci U S A 2007, 104:18235-18240.

33. Di Pietro A, Kajaste-Rudnitski A, Oteiza A, Nicora L, Towers GJ, Mechti N, Vicenzi E: TRIM22 inhibits influenza A virus infection by targeting the viral nucleoprotein for degradation. J Virol 2013, 87:4523-4533.

34. Sharma S, Mayank AK, Nailwal H, Tripathi S, Patel JR, Bowzard JB, Gaur P, Donis RO, Katz JM, Cox NJ, Lal RB, Farooqi H, Sambhara S, Lal SK: Influenza A viral nucleoprotein interacts with cytoskeleton scaffolding protein alpha-actinin-4 for viral replication. FEBS J 2014, 281:2899-2914.

35. Bean WJ: Correlation of influenza $A$ virus nucleoprotein genes with host species. Virology 1984, 133:438-442.

36. Scholtissek $\mathrm{C}$, Burger $\mathrm{H}$, Kistner $\mathrm{O}$, Shortridge KF: The nucleoprotein as a possible major factor in determining host specificity of influenza H3N2 viruses. Virology 1985, 147:287-294

37. Snyder MH, Buckler-White AJ, London WT, Tierney EL, Murphy BR: The avian influenza virus nucleoprotein gene and a specific constellation of avian and human virus polymerase genes each specify attenuation of avian-human influenza A/Pintail/79 reassortant viruses for monkeys. J Virol 1987, 61:2857-2863.

38. Brass AL, Huang I, Benita Y, John SP, Krishnan MN, Feeley EM, Ryan BJ, Weyer $J$, van der Weyden L, Fikrig E: The IFITM proteins mediate cellular resistance to influenza A H1N1 virus, West Nile virus, and dengue virus. Cell 2009, 139:1243-1254

39. Hao L, Sakurai A, Watanabe T, Sorensen E, Nidom CA, Newton MA, Ahlquist P, Kawaoka Y: Drosophila RNAi screen identifies host genes important for influenza virus replication. Nature 2008, 454:890-893.

40. Karlas A, Machuy N, Shin Y, Pleissner K-P, Artarini A, Heuer D, Becker D, Khali $H$, Ogilvie LA, Hess S: Genome-wide RNAi screen identifies human host factors crucial for influenza virus replication. Nature 2010, 463:818-822.

41. König R, Stertz S, Zhou Y, Inoue A, Hoffmann HH, Bhattacharyya S, Alamares JG, Tscherne DM, Ortigoza MB, Liang Y: Human host factors required for influenza virus replication. Nature 2009, 463:813-817.

42. Shaw ML, Stone KL, Colangelo CM, Gulcicek EE, Palese P: Cellular proteins in influenza virus particles. PLOS Pathog 2008, 4:e1000085.

43. Song J-M, Choi C-W, Kwon S-O, Compans RW, Kang S-M, Kim SI: Proteomic characterization of influenza $\mathrm{H} 5 \mathrm{~N} 1$ virus-like particles and their protective immunogenicity. J Proteome Res 2011, 10:3450-3459.

44. Sui B, Bamba D, Weng K, Ung H, Chang S, Van Dyke J, Goldblatt M, Duan R, Kinch MS, Li W-B: The use of random homozygous gene perturbation to identify novel host-oriented targets for influenza. Virology 2009, 387:473-481.
45. Fields S, Sternglanz R: The two-hybrid system: an assay for protein-protein interactions. Trends Genet 1994, 10:286-292.

46. Li S-X, Tong Y-P, Xie X-C, Wang Q-H, Zhou H-N, Han Y, Zhang Z-Y, Gao W, Li S-G, Zhang XC: Octameric structure of the human bifunctional enzyme PAICS in purine biosynthesis. J Mol Biol 2007, 366:1603-1614.

47. Kumar R, Nanduri B: HPIDB-a unified resource for host-pathogen interactions. BMC Bioinformatics 2010, 11(Suppl 6):S16-2105-2111-S2106-S2116.

48. Kroeker AL, Ezzati P, Coombs KM, Halayko AJ: Influenza A infection of primary human airway epithelial cells up-regulates proteins related to purine metabolism and ubiquitin-related signaling. J Proteome Res 2013, 12:3139-3151.

49. Kaplan JH: Biochemistry of Na, K-ATPase. Annu Rev Biochem 2002, 71:511-535.

50. Liu L, Zhou J, Wang Y, Mason RJ, Funk CJ, Du Y: Proteome alterations in primary human alveolar macrophages in response to influenza $A$ virus infection. J Proteome Res 2012, 11:4091-4101.

51. Mi S, Li Y, Yan J, Gao GF: Na(+)/K (+)-ATPase beta1 subunit interacts with $M 2$ proteins of influenza $A$ and $B$ viruses and affects the virus replication. Sci China Life Sci 2010, 53:1098-1105.

52. Falcón-Pérez JM, Dell'Angelica EC: Zinc transporter 2 (SLC30A2) can suppress the vesicular zinc defect of adaptor protein 3-depleted fibroblasts by promoting zinc accumulation in lysosomes. Exp Cell Res 2007, 313:1473-1483.

53. Liuzzi JP, Cousins RJ: Mammalian zinc transporters. Annu Rev Nutr 2004, 24:151-172

54. Huang L, Tepaamorndech S: The SLC30 family of zinc transporters - a review of current understanding of their biological and pathophysiological roles. Mol Asp Med 2013, 34:548-560.

55. Elliott DJ, Best A, Dalgliesh C, Ehrmann I, Grellscheid S: How does Tra2 $\beta$ protein regulate tissue-specific RNA splicing? Biochem Soc Transact 2012, 40:784-788.

56. Zhu J, Zou W, Jia G, Zhou H, Hu Y, Peng M, Chen H, Jin M: Analysis of cellular proteome alterations in porcine alveolar macrophage cells infected with 2009 (H1N1) and classical swine H1N1 influenza viruses. J Proteome 2012, 75:1732-1741.

57. Kang HW, Niepel MW, Han S, Kawano Y, Cohen DE: Thioesterase superfamily member 2/acyl-CoA thioesterase 13 (Them2/Acot13) regulates hepatic lipid and glucose metabolism. FASEB J 2012, 26:2209-2221.

58. Wei J, Kang HW, Cohen DE: Thioesterase superfamily member 2 (Them2)/ acyl-CoA thioesterase 13 (Acot13): a homotetrameric hotdog fold thioesterase with selectivity for long-chain fatty acyl-CoAs. Biochem J 2009, 421:311-322.

59. Brocker C, Carpenter C, Nebert DW, Vasiliou V: Evolutionary divergence and functions of the human acyl-CoA thioesterase gene (ACOT) family. Hum Genomics 2010, 4:411-420.

60. Cassimeris L, Becker B, Carney B: TOGp regulates microtubule assembly and density during mitosis and contributes to chromosome directional instability. Cell Motil Cytoskeleton 2009, 66:535-545.

61. Lakadamyali M, Rust MJ, Babcock HP, Zhuang X: Visualizing infection of individual influenza viruses. Proc Natl Acad Sci U S A 2003, 100:9280-9285.

62. Kosturko LD, Maggipinto MJ, D'Sa C, Carson JH, Barbarese E: The microtubule-associated protein tumor overexpressed gene binds to the RNA trafficking protein heterogeneous nuclear ribonucleoprotein A2. Mol Biol Cell 2005, 16:1938-1947.

63. Tai AW, Benita Y, Peng LF, Kim SS, Sakamoto N, Xavier RJ, Chung RT: A functional genomic screen identifies cellular cofactors of hepatitis $C$ virus replication. Cell Host Microbe 2009, 5:298-307.

64. Skoblov M, Marakhonov A, Marakasova E, Guskova A, Chandhoke V, Birerdinc A, Baranova A: Protein partners of KCTD proteins provide insights about their functional roles in cell differentiation and vertebrate development. Bioessays 2013, 35:586-596.

65. Kang KW, Lee SJ, Park JW, Kim SG: Phosphatidylinositol 3-kinase regulates nuclear translocation of NF-E2-related factor 2 through actin rearrangement in response to oxidative stress. Mol Pharmacol 2002, 62:1001-1010.

66. Kesic MJ, Simmons SO, Bauer R, Jaspers I: Nrf2 expression modifies influenza A entry and replication in nasal epithelial cells. Free Radic Biol Med 2011, 51:444-453.

67. Kish-Trier E, Hill CP: Structural biology of the proteasome. Annu Rev Biophys 2013, 42:29-49.

68. Sijts A, Sun Y, Janek K, Kral S, Paschen A, Schadendorf D, Kloetzel P-M: The role of the proteasome activator PA28 in MHC class I antigen processing. Mol Immunol 2002, 39:165-169.

69. Codina A, Love JD, Li Y, Lazar MA, Neuhaus D, Schwabe JW: Structural insights into the interaction and activation of histone deacetylase 3 by 
nuclear receptor corepressors. Proc Natl Acad Sci U S A 2005 102:6009-6014.

70. Baker AM, Fu Q, Hayward W, Lindsay SM, Fletcher TM: The Myb/SANT domain of the telomere-binding protein TRF2 alters chromatin structure. Nucleic Acids Res 2009, 37:5019-5031.

71. Kewitz S, Staege MS: Expression and regulation of the endogenous retrovirus 3 in Hodgkin's lymphoma cells. Front Oncol 2013, 3:179. doi: 10.3389/fonc.2013.00179.

72. Engdahl C, Naslund J, Lindgren L, AhIm C, Bucht G: The Rift Valley Fever virus protein $\mathrm{NSm}$ and putative cellular protein interactions. Virol J 2012, 9:139.

\section{Submit your next manuscript to BioMed Central} and take full advantage of:

- Convenient online submission

- Thorough peer review

- No space constraints or color figure charges

- Immediate publication on acceptance

- Inclusion in PubMed, CAS, Scopus and Google Scholar

- Research which is freely available for redistribution 